\title{
ANALISIS PERGESERAN AKIBAT GEMPA BUMI SUMATERA 11 APRIL 2012 MENGGUNAKAN METODE GPS CONTINUE (Studi Kasus : Samudera Hindia)
}

\section{DISPLACEMENT ANALYSIS OF APRIL $11^{\text {TH }} 2012$ SUMATERA EARTHQUAKE BY USING GPS CONTINUE METHODE (Case Study : Indian Ocean)}

\author{
Meiriska Yusfania ${ }^{1}$, Fahruddin Ulinnuha Ihsan ${ }^{1}$, Mokhamad Nur Cahyadi ${ }^{1}$ \\ ${ }^{1}$ Institut Teknologi Sepuluh Nopember Surabaya \\ Email: yusfania_mei@geodesy.its.ac.id
}

\begin{abstract}
Abstrak
Prinsip pemantauan deformasi secara kontinu yaitu pemantauan terhadap perubahan koordinat beberapa titik yang mewakili sebuah fenomena gempa bumi dari waktu ke waktu. Metode ini, menggunakan beberapa alat penerima sinyal GPS yang ditempatkan pada beberapa titik pantau pada area gempa bumi. Data dan informasi deformasi permukaan selanjutnya digunakan untuk mengungkapkan karakteristik dari aktivitas gempa bumi. Gejala deformasi gempa bumi akan menyebabkan pergeseran posisi suatu titik sekitar gempa. Pergeseran tersebut bisa terjadi baik secara horizontal maupun vertikal.Pada penelitian kali ini mengambil salah satu gempa yang terjadi pada bulan april tahun 2012 dengan magnitude 8.6. Untuk melakukan analisis deformasi diperlukan menghitung vektor pergeseran dan nilai pergeseran yang mengacu pada titik-titik stasiun GPS Kontinyu Sumatran GPS Array (SUGAR) yang tersebar di lima stasiun yaitu BITI, BSIM, BTHL, LEWK, PBLI, dan NTUS. Analisis deformasi dilakukan dengan melihat pergeseran yang terjadi pada saat sebelum gempa, dan sesudah gempa. Setelah dilakukan pemrosesan dari kedua waktu tersebut didapatkan nilai perubahan $0,3-2,4$ meter dari setiap stasiun terdekat dengan pusat gempa. Analisis karakteristik deformasi Gempa Sumatera 2012 ini tergolong fenomena Strike-slip faults yang merupakan potongan vertikal di mana blok sebagian besar telah pindah secara horizontal. Jika blok berlawanan pengamat bergerak ke kanan, gaya slip disebut right lateral jika blok bergerak ke kiri, gerakan ini disebut left lateral.
\end{abstract}

Kata Kunci : gempa bumi, deformasi, GPS, strike-slip faults

\begin{abstract}
The principle of continuous deformation monitoring is monitoring the coordinates changes from several points that represent a phenomenon of earthquakes time to time. This method, take a data by using several GPS receiver placed at several monitoring points in the earthquake area. Data and information on surface deformation is then used to reveal the characteristics of earthquake activity. Symptoms of earthquake deformation would lead to a shift in the position of a point around the quake. Such shifts can occur both horizontally and vertically. In the final project took one of the earthquake that occurred in April of 2012 with a magnitude of 8.6. To perform the necessary deformation analysis calculated the vector shift and the shift value refers to the points of continuous GPS stations Sumatran GPS Array (SUGAR) spread across five stations that BITI, BSIM, BTHL, LEWK, PBLI, and NTUS. Deformation analysis was done by looking at the shift in the time before the earthquake, and after the earthquake. After the processing of the obtained value change of 0.3-2.4 meters of each station closest to the epicenter. characteristics of the Sumatran earthquake in 2012 is quite a phenomenon Strike-slip faults that are vertical pieces where blocks have largely been moved horizontally. If the block opposite the observer moves to the right, called the right lateral slip style if the block moves to the left, is called the left lateral movement.
\end{abstract}

Keyword : earthquake, deformation, GPS, strike-slip faults 


\section{PENDAHULUAN}

\section{LatarBelakang}

Indonesia merupakan negara yang memiliki potensi gempa. Hal ini terjadi karena letak dari Indonesia yang merupakan pusat pertemuan dari lempeng-lempeng antara lain Eurasia, Filipina, Caroline, Indo-Australia, Pasifik dan beberapa lempeng minor lainya (Hamilton 1979). Selain itu juga disebabkan oleh aktifitas tektonik dari lempeng-lempeng tersebut. Lempeng-lempeng tersebut terus bergerak seperti halnya lempeng Eurasia dan Indo-Australia yang memiliki pergerakan rata-rata kearah utara, sedangkan pergerakan lempeng Filipina cenderung kearah barat laut (Hamilton 1979 dalam USGS, 2011). Terkait dengan lempeng filipina, lempeng Caroline memiliki pergerakan kearah tenggara di bagian palung Aru dan kearah barat laut di bagian palung Yap (Seno 1992 dalam USGS, 2011).

Pulau Sumatra termasuk salah satu pulau terbesar di Indonesia. Pulau ini merupakan salah satu wilayah dengan aktifitas tektonik paling aktif di dunia. Sumatra mengakomodasi tumbukan lempeng Indo-Australia yang men-subduksi lempeng Eurasia dengan kecepatan 5-6 cm/tahun (Prawirodirdjo, 2000). Hal ini mengakibatkan Pulau Sumatera rawan terjadi gempa tektonik yang di sebabkan dari pergerakan lempeng tersebut. Salah satu gempa besar yang terjadi pada tahun 2010 adalah gempa Mentawai dengan magnitude gempa 7.7 pada lokasi koordinat $99^{\circ} 93^{\prime} \mathrm{BT} ; 3^{\circ} 61^{\prime} \mathrm{LS}$ dan kedalaman 10 $\mathrm{km}$.

Pemantauan deformasi dengan GPS dapat di bagi dua yaitu pemantauan secara kontinu dan pemantauan secara episodik. Prinsip pemantauan deformasi secara kontinu yaitu pemantauan terhadap perubahan koordinat beberapa titik yang mewakili sebuah fenomena gempabumi dari waktu ke waktu. Metodeini, menggunakan beberapa alat penerima sinyal (reciever) GPS yang ditempatkan pada beberapa titik pantau pada area gempabumi, serta pada suatu pusat pemantau (stasiun referensi) yang merupakan pusat pemrosesan data. Data dan informasi deformasi permukaan selanjutnya digunakan untuk mengungkapkan karakteristik dari aktivitas gempabumi. Gejala deformasi gempabumi akan menyebabkan pergeseran posisi suatu titik sekitar gempa. Pergeseran tersebut bisa terjadi baik secara horizontal maupun vertikal.

\section{METODOLOGI PENELITIAN}

\section{Data Dan Peralatan}

\section{- Data}

Data yang dibutuhkan dalam penelitian ini adalah:

Data GPS dari stasiun pemantauan SUGAR 27

Maret 2012 sampai 26 Maret 2012 Dengan jumlah titik adalah 6 stasiun dimana gempa tersebut terjadi pada tanggal 11 April 2012.

- Peralatan

Perangkat Keras

1. Komputer Pengolahan

Perangkat Lunak

1. GPS Tools

2. Matlab

3. Microsoft Execl 2013

4. GMT Generic Mapping Tools

\section{Metode Penelitian}

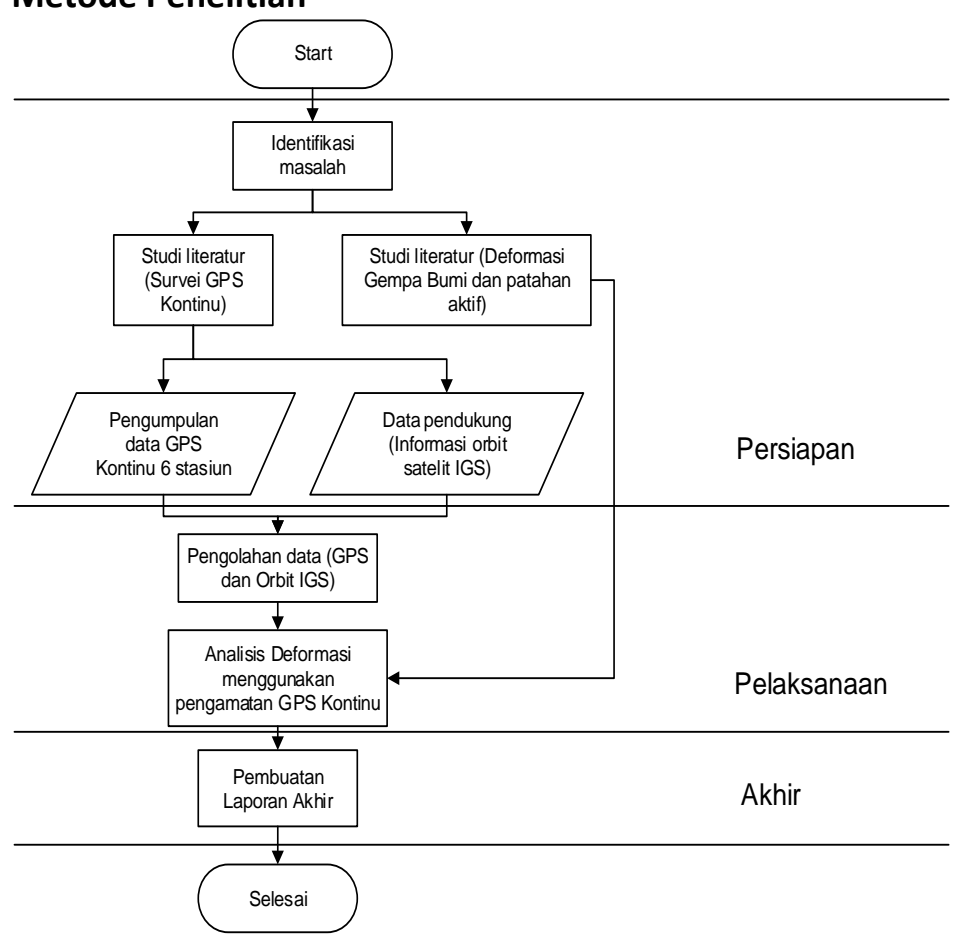

Gambar 1.Diagram Alir Penelitian

Penjelasan dari diagram alir di atas dijabarkan di bawah ini:

a. Identifikasi Masalah 
Permasalahan yang diangkat dalam penelitian ini adalah bagaimana menganalisis perubahan deformasi dan kecepatan pergeseran dari titiktitik pemantauan deformasi.

b. Studi Literatur

Tahapan ini bertujuan untuk mendapatkan referensi yang berhubungan dengan penelitian yang akan dilakukan. Studi literatur yang dilakukan meliputi:

i. Pengkajianmetode-metode pemantauan deformasi Gempa Bumi

ii. Studi literature mengenai anilasa deformasi dan kecepatan pergeseran titiktitik pemantaun deformasi menggunakan GPS.

c. Pengumpulan Data

Pada tahap ini, dilakukan pengumpulan semua data yang diperlukan untuk penelitian. Data diperoleh dari hasil pemantaun menggunakan GPS di stasiun-stasiun SUGAR pemantauan secara kontinu pada tahun 2012.

d. Pengolahan Data

Pada tahapan ini, data yang dikumpulkan kemudian diproses dengan menggunakan GPS Tools (software pengolah data GPS). Lalu ditransformasikan ke koordinat toposentrik untuk menghitung besar deformasi dan arah vektor.

e. Analisis Hasil Pengolahan

Setelah data selesai diolah, maka akan dilakukan analisis terhadap hasil pengolahan. Pada tahap ini, hasil dari pengholahan akan dianalisis perubahan dan kecepetan pergeseran deformasinya dari 15 hari sebelum dan 15 hari sesudah gempa tanggal 11 April 2012.

f. Pembuatan Laporan Akhir

Tahapan ini merupakan tahap akhir dari penelitian yang dilakukan.

\section{HASIL DAN PEMBAHASAN}

Data yang rinex yang di dapat diolah dengan menggunakan software GPSTools dengan menggunakan metode perhitungan Precise Point Positioning (PPP) yang membutuhkan parameter tertentu. Adapun tiga parameter tersebut adalah koreksi orbit satelit yang mempunyai format igsxxx.sp3, kemudian koreksi waktu dengan format igsxxx.clk, dan parameter koreksi rotasi bumi dengan format igsxxx.eph. Setelah semua data disiapkan dilanjutkan dengan pengolahan menggunakan GPSTools.

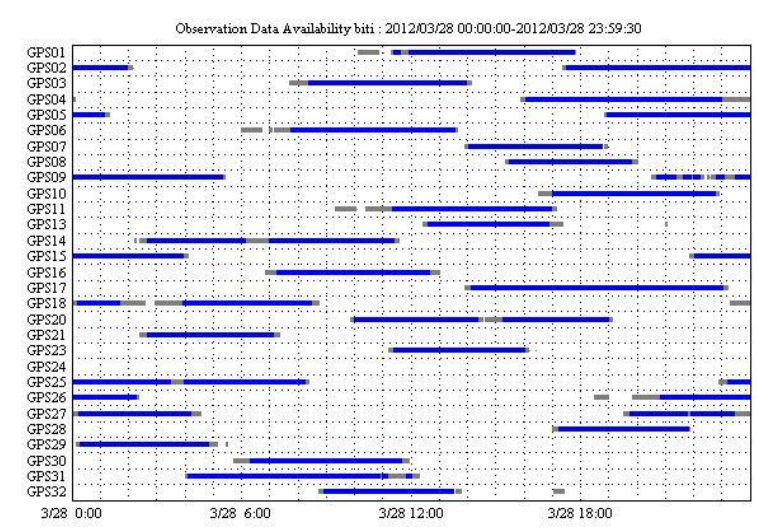

Gambar 2. Ketersedian Data Observasi GPS pada Waktu Pengamatan Gempa di Stasiun BITI

Merupakan contoh observation data stasiun BITI pada hari pertama atau pada day of year (doy) ke 88 (GPSDAY). Dalam satu hari terdapat 6 stasiun yang diamati dan diproses data pergeseran GPS selama tiga puluh satu hari untuk analisis pergeseran akibat gempa bumi Sumatra 2012.

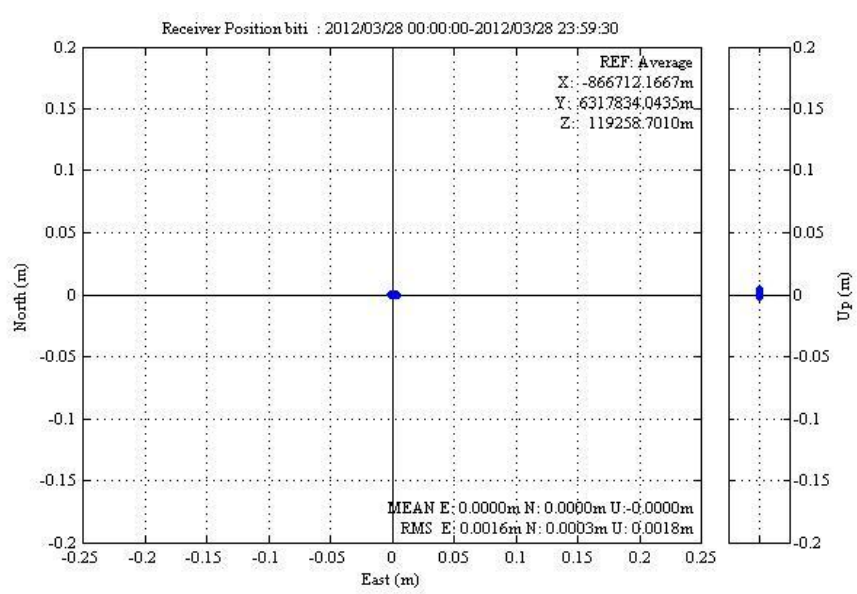

Gambar 3. Posisi Receiver GPS

Gambar 3 menunjukan receiver position di stasiun BITI yang fix pada hari pertama pengamatan yaitu -866712.1667 sumbu $x, 6317834.0435$ sumbu $y$, dan 119258.7010 sumbu z. Gambar di atas disajikan lengkap dengan RMS error sebesar $1.6 \mathrm{~mm}$ pada sumbu $x, 0.3 \mathrm{~mm}$ pada sumbu $y$, dan $1.8 \mathrm{~mm}$ pada sumbu $z$. 

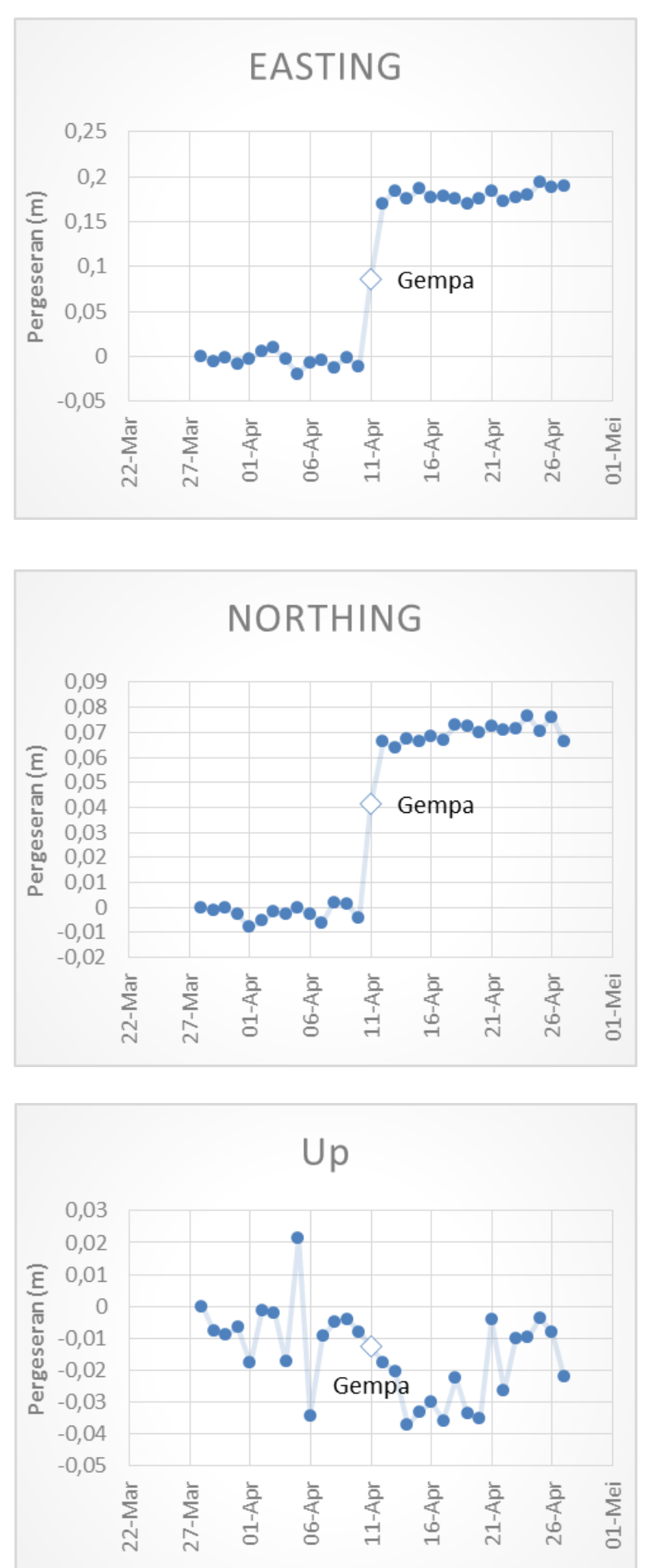

Gambar 4. Plotting Grafik Pergeseran Eathing, Northing dan Up Sebelum dan Setelah Gempa Sumatera 2012

\section{Efek Model Euler Pole}

Rata-rata stasiun SUGAR (Sumatera GPS Aray) mendapatkan pengaruh dari blok sunda. Blok sunda merupakan suatu blok yang melintasi sebagian besar regional Asia Tenggara termasuk perairan dangkal yang terletak di barat dari pulau Sumatera. (Henri, 2013). Perilaku pergerakan suatu blok dapat didefinisikan dari rotasi Euler dan vector pergeseran seismik (deformasi elastik). Ini berarti nilai kecepatan dari stasiun SUGAR yang dilewati oleh blok sunda mengalami perubahan efek dari blok sunda. Pada penelitian ini digunakan model ITRF 2000 dengan pusat rotasi di bujur -86.90 dan lintang 38.90 serta kecepatan rotasi $0.322 \mathrm{deg} /$ Myr. (Bock, et al, 2003). Berikut adalah tabel dari kecepatan blok sunda sesuai stasiun pengamatan.

Tabel 1. Efek Pergeseran Euler Pole pada Stasiun Pengamatan

\begin{tabular}{lll}
\hline stasiun & $\mathrm{E}(\mathrm{m})$ & $\mathrm{N}(\mathrm{m})$ \\
\hline BSIM & -0.002 & 0.023 \\
BITI & -0.002 & 0.023 \\
BTHL & -0.002 & 0.023 \\
LEWK & -0.001 & 0.024 \\
NTUS & -0.005 & 0.023 \\
PBLI & -0.002 & 0.023 \\
\hline
\end{tabular}

\section{Analisis Pergeseran Fase Interseismic}

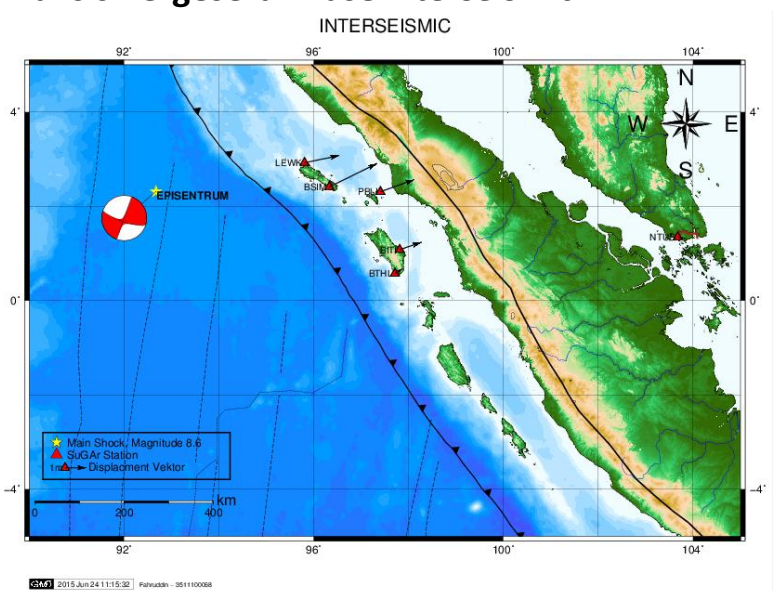

Gambar 5. Arah Pergeseran Interseismic

Pergeseran yang terbesar terjadi padas tasiun BITI dengan besar pergeseran $2.498 \mathrm{~m}$ karena letak 
dari stasiun ini paling dekat dengan pusat gempa yang ada di Samudera Hindia. Sedangkan besar pergeseran stasiun yang lain adalah $1.066 \mathrm{~m}$ untuk stasiun BSIM, 0.387 untuk stasiun BTHL, $1.671 \mathrm{~m}$ untuk stasiun LEWK, $0.345 \mathrm{~m}$ untuk stasiun NTUS, dan $1.693 \mathrm{~m}$ untuk stasiun PBLI. Pada fase ini semua stasiun bergeser ke arah timur laut.

Hasil dari plotting di GMT menunjukkan bahwa pergerakan stasiun lebih banyak kearah timur laut dimana sesuai dengan deskripsi gempa dari (USGS, 2012) dimana gempa yang terjadi menandakan adanya pergerakan slip left-lateral yang bergerak ke arah timur laut.

Tabel 2. Fase Interseismic

\begin{tabular}{llll}
\hline Stasiun & Ve $(\mathrm{m})$ & Vn $(\mathrm{m})$ & $\begin{array}{l}\text { Besar } \\
\text { Pergeseran } \\
(\mathrm{m})\end{array}$ \\
\hline BSIM & 1.016702 & 0.32353 & 1.066937274 \\
BITI & 2.250899 & 1.084013 & 2.498325447 \\
BTHL & 0.33532 & 0.19337 & 0.387081101 \\
LEWK & 1.642343 & 0.310317 & 1.671402404 \\
NTUS & 0.332905 & -0.09416 & 0.34596502 \\
PBLI & 1.602063 & 0.547665 & 1.693086289 \\
\hline
\end{tabular}

\section{Analisis Pergeseran Fase Postseismic}

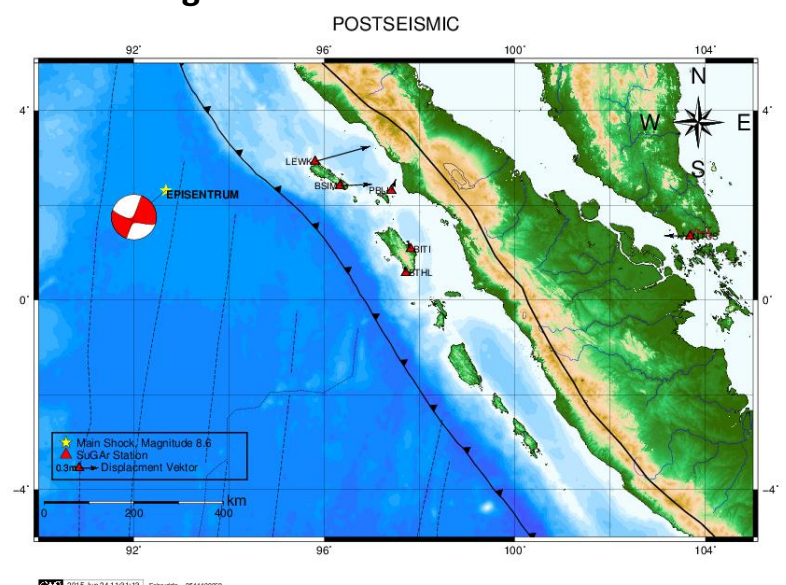

Gambar 6. Arah Pergeseran Postseismic

Pergeseran yang terbesar terjadi pada stasiun LEWK dengan besar pergeseran $0.849 \mathrm{~m}$ ke arah timur laut karena letak dari stasiun ini paling dekat dengan pusat gempa yang ada berada di Samudera Hindia. Sedangkan besar pergeseran stasiun yang lain adalah $0.097 \mathrm{~m}$ ke arah timur untuk stasiun BSIM, $0.477 \mathrm{~m}$ ke arah barat laut untuk stasiun $\mathrm{BITI}, 0.059 \mathrm{~m}$ ke arah barat laut untuk stasiun BTHL, $0.370 \mathrm{~m}$ ke arah barat laut untuk stasiun NTUS, dan $0.156 \mathrm{~m}$ ke arah timur laut untuk stasiun PBLI.

Tabel 3. Fase Postseismic

\begin{tabular}{llll}
\hline Stasiun & Ve $(\mathrm{m})$ & Vn $(\mathrm{m})$ & $\begin{array}{l}\text { Besar } \\
\text { Pergeseran } \\
(\mathrm{m})\end{array}$ \\
\hline BSIM & -0.04027 & 0.088298 & 0.097046112 \\
BITI & 0.477715 & -0.0006 & 0.477715523 \\
BTHL & -0.01453 & 0.057763 & 0.059561733 \\
LEWK & 0.824214 & 0.204524 & 0.849210186 \\
NTUS & -0.36971 & -0.01464 & 0.370000211 \\
PBLI & 0.069503 & 0.140208 & 0.156489662 \\
\hline
\end{tabular}

\section{PENUTUP}

Arah pergeseran yang terjadi pada 5 stasiun (BITI, BSIM, BTHL, LEWK, dan PBLI) pada saat fase Interseismic adalah pergerakan ke arah timur laut. Kemudian pada saat fase Postseismic terdapat 2 stasiun (BITI dan BTHL) yang mengalami pergerakan ke arah barat laut dan 3 stasiun lainnya (BSIM, LEWK, dan PBLI) mengalami pergerakan ke arah timur laut.

\section{DAFTAR PUSTAKA}

Abidin, H.Z. 2000. Penentuan Posisi dengan GPS dan Aplikasinya. PT Pradnya Pramita, Jakarta. Cetakan kedua.

Andreas, H. 2007. Karakteristikdeformasi strain and stress. Prodi TeknikGeodesidanGeomatika ITB

Kouba J. and Heroux P.. 2001. GPS Precise Point Positioning Using IGS Orbit Products. GPS Solutions.

NASA, (7 April 2015), Earth Fact Sheet. Alamatsitus: http://nssdc.gsfc.nasa.gov/planetary/facts heet/earthfact.html.

Putra, Adi. 2012. Studi Kinerja Software On-Line PPP (PRECISE POINT POSITIONING) Dalam Pengolahan Data Survey GPS. Prodi Teknik Geodesi dan Geomatika ITB. 